\title{
On Erotically Marked Objects from the Perspective of Object Studies
}

Grażyna Gajewska 
Grażyna Gajewska

\section{On Erotically Marked Objects from the Perspective of Object Studies}

DOI: 10.18318/td.2015.en.1.14

\section{Eroticism: Between Nature and Culture}

In his 1993 essay "The Double Flame: Love and Eroticism"1, the Mexican poet and essayist Octavio Paz considers the intricate relationship between sex, eroticism and love. Though connected, the three cannot be regarded as synonymous. Paz illustrates this phenomenon of simultaneous connectedness and difference using the metaphor of fire and the flame: nature kindles the fire of sex, over which quivers the subtle, blue flame of love. Neither red nor blue flames can exist without fire, and yet they are distinct from the fire above which they hover. The Mexican intellectual stresses that sex is the least human element of the triad, and the reason is that it applies to many other species besides homo sapiens, and its goal is reproduction. While sex belongs to the sphere of nature, the flames of eroticism cannot be placed unambiguously in the same sphere, as they belong rather to the field of culture. Eroticism is not some "unnatural" act, but it rather transcends the act, engaging unused deposits of sexual energy and desire. On the one hand, therefore, eroticism is closely linked to nature (we would not be erotic beings
Grażyna Gajewska

- professor of the

UAM, director of the Department of Contemporary

Culture and

Multimedia in

the Institute of

European Culture

of the UAM. Author

of two monographs

and editor of a few

other books, as well as of a few dozen of articles in the field of literary and cultural studies. Contact: gajewska@amu. edu.pl

1 Octavio Paz, The Double Flame: Love and Eroticism, translated by Helen Lane (Harcourt Brace \& Company: 1996). 
if we were not sexual animals first), and on the other, by separating desire from the reproductive function, it shifts the surplus of energy and the creativity that arises from it into the field of culture.

Zygmunt Bauman, following Paz's thoughts, writes: "That surplus is a standing invitation to cultural inventiveness. The uses to which that reproductively redundant and wasted excess may be put are a cultural creation"2. At the same time, Bauman emphasizes the impossibility of "liberating" that (cultural) eroticism from its (natural) sexuality: "(...) the reproductive function of sex is simultaneously the indispensable condition and a thorn in the flesh of eroticism; there is an unbreakable link, but also a constant tension between the two - that tension being as incurable as the link is unbreakable"3. While Bauman notes the ambiguous relationship between sex and eroticism and the impossibility of the latter's separation from the sphere of nature, George Bataille makes a clear distinction between sexuality and eroticism, and stresses that the move from the former to the latter is, in essence, a transgression from animal to human. In Erotism: Death and Sensuality (first published in English translation in 1962) 4 , he writes: "Eroticism is the sexual activity of man to the extent that it differs from the sexual activity of animals. Human sexual activity is not necessarily erotic but erotic it is whenever it is not rudimentary and purely animal"5. Eroticism is thus presented as a specifically human category, and is by the same token inscribed into the Western notion of the opposition between nature and nurture and the emphasis on the exclusive attributes that separate humans from the world of animals ${ }^{6}$.

2 Zygmunt Bauman, "On Postmodern Uses of Sex" in Love and Eroticism, ed. Mike Featherstone (London: Sage, 1999), 20.

Bauman, "On Postmodern Uses of Sex", 20.

4 George Bataille, Erotism: Death and Sensuality, trans. Mary Dalwood (San Francisco: City Lights Books, 1986).

5 Ibid., 29.

6 The hierarchical relationship between humans and animals, or, more broadly, between humans and animate nature, has its roots in the Aristotelian and Judeo-Christian traditions. In his treatise On the Soul, Aristotle presented a tripartite and hierarchical division of beings. According to this concept, the lowest rung is occupied by plants, above them are animals, and at the top are humans. The criterion for separating plants from animals and people was both the soul (according to Aristotle, plants have vegetative souls, i.e. the kind found in all living beings) and the belief that animals are immobile and insensitive. Animals, in the philosopher's view, were by contrast endowed with both a vegetative soul and senses (though some have all the senses, while others only have some or just one, that of touch). Some animals also have an imagination, but lack rational perception. Reason, in Aristotle's view, is a special substance 
From a contemporary - particularly posthumanist - perspective, the opposition between humans and animals, or rather humans and non-human animals, is becoming increasingly fluid, and even the sexual and erotic sphere is no longer an area characterized by a clear distinction between needs and behavior? This does not, however, mean that we have only two paths to choose from in our thinking about eroticism: one with a clearly anthropocentric, humanist and culturalist tint that locates eroticism on the side of culture, in opposition to nature, or the other: a posthumanist path that extracts the interdependence between nature and culture and draws attention to the fluidity between the animal and the human. In the non-anthropocentric view, posthumanism is merely one of several possible options. At least two other non-anthropologically tinted strains of thought are currently being developed in parallel to posthumanism: transhumanism and material anthropology, among which the latter appears to be particularly inspiring with regard to extracting specific and hitherto unexamined aspects of eroticism. The relativity of people and objects and the symbiotic relationships between humans and both the animate and inanimate worlds emphasized by anthropological theorists enables one to examine eroticism as a sphere that exists and changes as a result of the influence of things, or rather as a result of humans entering into relationships with things/objects. More precisely, the erotic attractiveness of humans is largely shaped by things: shoes, clothing, accessories and jewelry. Furthermore, some objects such as shoes (particularly heels), lingerie and garters even appear to have erotic characteristics. In this article I propose that we examine these objects as active participants of erotic games, rather than passive things that are somewhere beyond people and the sexual and erotic sphere. In my non-anthropocentric view of eroticism, I emphasize the relativity, symbiosis and participation of things in shaping the erotic sphere

that is different from the vegetative and sensitive soul. Its formation in humans constitutes a separate problem, but the distinction between souls specific to various life forms was decisive in Aristotle's hierarchical division of beings. See Aristotle, On the Soul, trans. Hugh Lawson-Tancred (London: Penguin Books, 1986). In the Old Testament story of the creation of the world and humankind, on the other hand, we read that God said: "Let us make mankind in our image, in our likeness, so that they may rule over the fish in the sea and the birds in the sky, over the livestock and all the wild animals, and over all the creatures that move along the ground". Humans are not only separated from the rest of nature, as the only beings created in the image of God, but have also been given the right to rule over animals. This finds its confirmation in a later part of the Book of Genesis: "Rule over the fish in the sea and the birds in the sky and over every living creature that moves on the ground". Non-human beings were given to humans so that they might fulfill the will of God. Genesis 1:26, 1:27, The Holy Bible, New International Version (Grand Rapids: Zondervan Publishing House, 1984).

7 Intimacy (including sexual intimacy) across species boundaries is discussed in Monika Bakke, Bio-transfiguracje. Sztuka i estetyka posthumanizmu (Poznań: Wydawnictwo UAM), 119-125. 
of human life, and thus attribute a certain agency (but not intentionality) to objects.

\section{Towards a Non-Anthropocentric Humanism}

There are three varieties of contemporary non-anthropocentric humanism being developed. My aim is not to present each of these strains, but to point out the differences between them and to offer a more detailed presentation of material anthropology that will serve as the theoretical foundation of my discussion of eroticism. The first variety, known as posthumanism, questions the clear distinction between humans and animals (hence the use of the terms "humans" and "non-human animals" by posthumanist thinkers) and unmasks the arbitrary assumptions behind the hierarchical structure of animated beings: plants - animals - humans. This convention seeks to overcome humans' condescending stance towards other life forms and their exploitative behavior towards nature in favor of building symbiotic interdependencies between various beings.

In the second variety, known as transhumanism, the emphasis is placed on tightening the relationship between people and high technology. This approach is linked to developments in the fields of medicine and technological science. The goal of transhumanism can be described as autoevolution: the desire to liberate humans from random biological evolution and to replace it with controlled development. If we function in symbiotic relationships with other life forms and inanimate matter; if we do not think of humans as a complete whole, then, at least from the transhumanist perspective, there is no reason for us to believe that the development of humankind is over. The stances and postulates of the transhumanists are not synonymous with those espoused by posthumanists. Transhumanism does not preclude an anthropocentric outlook; indeed, the point is to use technology for the purpose of improving humans' quality of life and to improve humans themselves. In this sense, transhumanists pursue a model of human self-perfection that, from the posthumanist standpoint, is a conservative one, as they do not venture beyond the concept of humans as the standard by which all things are measured. Transhumanists, meanwhile, reject essentialist visions of the human subject, question the completeness of humans, proclaim the advent of a new being that operates in tight symbiosis with machines and electronics, and, consequently, their projects open up that which is human to that which is non-human.

In the case of the third variety, described as material anthropology or the study of objects, attention is focused on material culture, or "materialized" culture. However, this approach cannot be treated as a mere extension or 
duplication of the study of material culture initiated several decades ago by historians associated with the Annales School (e.g. Fernand Braudel) ${ }^{\mathbf{8}}$. The study of objects differs from modernist studies on material culture in its approach to the subject of study, its methodology and particularly the academic questions it poses - questions that are situated in different contexts than those posed several decades ago' ${ }^{9}$. On the one hand, this new approach to material culture is the product of contemporary thinkers' critical analysis of the modernist approach to the topic, and on the other, their distancing themselves from the ontology and epistemology that developed as part of the so-called linguistic turn. This distance, perhaps even intellectual boredom, finds its expression in the 2003 article by the archaeologist Bjørnar Olsen, Material Culture after Text:Re-Membering Things ${ }^{10}$. Olsen argues that objects ought to be returned their reality and materiality, and stresses that the linguistic and literary perspectives are rather useless with regards to this issue. He attempts to bring the objectiveness of objects back into the fold of archaeological studies, yet his observations on the ontological and epistemological shift in the approach to things are themselves part of a broader spectrum of posthumanist reevaluations. For example, Olsen emphasizes that "that things, all those physical entities we refer to as material culture, are beings in the world alongside other beings, such as humans, plants and animals"11. He makes no attempt to blur the differences between these beings, but he does observe that this difference is one "that should not be conceptualized according to the ruling ontological regime of dualities and negativities; it is a non-oppositional or relative difference facilitating collaboration, delegation and exchange"12. In this perspective, it is not the symbolic value (meaning) of objects in culture that is stressed, nor their usefulness or consumption by people that is emphasized, but the interdependency, relativity and delegation between people and things. This perspective encourages us to treat things as relevant co-participants of social life - an approach that contrasts with the unambiguous concept of humans as the only or most important agent of transformation in the world.

8 Fernand Braudel. Capitalism and Material Life: 1400-1800, trans. Miriam Kochan (London: Weidenfeld and Nicolson, 1973).

9 See Ewa Domańska, Historie niekonwencjonalne. Refleksja o przeszłości w nowej humanistyce, (Poznań: Wydawnictwo Poznańskie, 2006).

10 Bjørnar Olsen, "Material Culture after Text: Remembering Things", Norwegian Archeological Review 36, no. 2 (2003): 87-104.

12 Ibid., 88. 
The British anthropologist Alfred Gell stresses the social functions of things in his 1998 book Art and Agency: An Anthropological Theory. Rather than follow the beaten path of presenting works of art in the context of sociocultural shifts caused by humans, Gell treats art objects as subjects participating actively in those shifts. At the same time, the author of Art and Agency distances himself from the semiotic research perspective that examines works of art as a system of signs that "reflects" social reality:

In place of symbolic communication, I place all the emphasis on a $\mathrm{g}$ e $\mathrm{c} y$, intention, causation, result, and transformation. I view art as a system of action, intended to change the world rather than encode symbolic propositions about it. The 'action'-centered approach to art is inherently more anthropological than the alternative semiotic approach because it is preoccupied with the practical mediatory role of art objects in the social process, rather than with the interpretation of objects 'as if' they were texts ${ }^{\mathbf{1 3}}$.

This research perspective enables Gell to see objects as agents or co-agents of events. While he does not endow things with intention, he does claim that that intentional beings perform their actions through these things.

Another thinker who emphasizes the agency of things is the Dutch anthropologist Peter Pels. According to him, objects come alive in a social space and that is where, in a sense, they begin to "act" or "reflect" the meanings ascribed to them by people. Pels emphasizes the feedback loop between people and objects as well as their mutual influence on each other, meaning that "things talk back" to us ${ }^{\mathbf{1 4}}$. According to him, "not only are humans as material as the material that mold them, but humans themselves are molded, through their sensuousness, by the 'dead' matter with which they are surrounded"15. In this perspective, it becomes crucial to emphasize the material (carnal) foundations of human existence, a consequence of which is the perception of the human subject as always embodied and also connected to other organic and non-organic kinds of matter. One can hardly overestimate the scale of this mutual influence, as it plays a key role in socialization. We inhabit a complex web of relationships with human and non-human others, anchored as we are in material surroundings

13 Alfred Gell, Art and Agency: An Anthropological Theory (Oxford: Oxford University Press, 1998), 6.

Peter Pels, "The Spirit of Matter: On Fetish, Rarity, Fact, and Fancy" in Border Fetishisms: Material Objects in Unstable Spaces, ed. Patricia Spyer (New York: Routledge, 1998), 91-121.

Pels, "The Spirit of Matter: On Fetish, Rarity, Fact, and Fancy", 101.

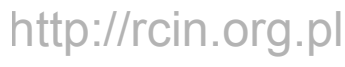


that we create, transform and disseminate as we occupy them. Yet the point is not to treat matter (including material human bodies) as yet another topic to be addressed in our examination of contemporary manifestations of commercialism and consumerism, but to demonstrate that people are not isolated from the material and objectified world. It is not only humans, but also nonhumans, including objects, that participate in the "weaving" of the complex web of social relations. In this perspective, the "discourse of things" is set in human discourse $\mathrm{e}^{\mathbf{1 6}}$ and is governed by certain pragmatics involving identity building, social relations, the discourse of mourning, justice, fashion, etc. To this list of defined types of pragmatics one may also add eroticism; indeed, human erotic attractiveness is largely shaped and manifested through lingerie, clothing, accessories and jewelry. When discussing such relationships between people and things, one should also keep in mind the objects that are not outside of us in the physical sense, but have come to share the space of our biological bodies; they have literally become embodied. A ready example is that of silicone breast implants that are used not only to replace a mastectomy patient's missing mammary gland or to correct a birth defect, but also to increase the size of existing breasts, which is often perceived as improving the visual attractiveness of the female body. Another example of the erotic relativity between people and things is the fascination and admiration evoked by artificial anthropomorphic bodies, i.e. mannequins such as those displayed in department stores and shopping centers. Contrary to the popular claim that mannequins fascinate us because they resemble people and that, in their non-living materiality, they represent living bodies, I claim that the point is not that they represent living bodies, but

16 I refer here to Ewa Domańska, who describes this view of the study of things as redundant, as it is still entrenched in the human perspective: "Paradoxically, subjectified objects share the fate of others who cannot speak for themselves (the dead, women, children, minorities, the defeated, etc.). Inevitably, it is people who speak in their name, and that means that the discourse of things will always be entrenched in us, in human discourse, in our needs and expectations, and will always be subject to certain pragmatics, whether they involve the acquisition of knowledge, identity building, social relations, or the discourse of mourning, justice, memory, heritage, fashion, etc". Ewa Domańska, "Humanistka nie-antropocentryczna a studia nad rzeczami", Kultura Współczesna, no. 3 (2008): 13-14. Domańska speaks in favour of locating the studies devoted to objects in the perspective of the humanities which renounce the idea of man as the measure of all things. In this perspective the studies devoted to things would be supposed to refer to "the pursuit of a resistant object which opposes human cognition and the attempts to appropriate this object by language". Ibid., 10. Despite the interesting supposition which open a broad field to a deconstruction and reformulation of trite ways of thinking about things, I consider that this proposition is not so useful for the analysis of the phenomena that I conduct. A more adequate methodological proposition which functions within the framework of the studies devoted to objects is the one that Domańska refers as a conservative proposition. In this reactionary version (let us repeat this point) the discourse of objects is installed into the human discourse and it is directed by a certain kind of pragmatics.

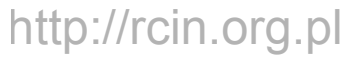


that they present a fantasy, one that often has an erotic tinge. In fact, the point of reference is not a body made of real flesh and blood, often imperfect, crippled and aging, but the fantasy of the perfect lover coming to life ${ }^{17}$. From the psychoanalytical perspective, a mannequin - particularly a quasi-female mannequin - is the apparition of "the woman who could fill out the lack in man, the ideal partner with whom sexual fulfilment would finally be possible, in short, The Woman who (...) does not exist"18.

Psychoanalytic theory can be useful not just in the search for erotic tension between people and the artificial bodies of storefront mannequins, but also in analyzing the erotic functions of clothing, footwear and lingerie. The central, organizing concept of this discourse will be the fetish, both in the Freudian (sexual fetish) and Marxian (commodity fetishism) senses. In the opinion of Peter Pels, the aforementioned theoretician of material anthropology, both of these paths in Western European thought reinstated the concept of the fetish (fetisso) - which had previously existed outside Europe - as a way of experiencing an object that changes how it functions in society ${ }^{\mathbf{1 9}}$. In other words, some objects escape the boundaries of standard use defined by everyday practice, and function in a magical, religious order that is not quite subject to utilitarian or commercial regimes of evaluation (pricing). That is not to say that these things are granted intentionality or that they act "of their own accord" (though in the magical order, action is ascribed to them and they are equally often perceived as living things), but rather that due to the way they function in a given community, they elude attempts at rationalization, and particularly quantification, including commercial quantification. This concept of the fetish is most frequently used in the analysis of devotional objects such as those associated with practices like the manufacture and veneration of the images of saints ${ }^{\mathbf{2 0}}$, though it can also be applied in the analysis of erotically marked objects. The effect of this erotic "untranscended materiality" becomes somewhat more apparent when we observe that clothing, shoes, lingerie and accessories serve not only the strictly pragmatic purpose of protecting their wearers from the elements, but also allow

17 The erotic marking of mannequins is discussed in Grażyna Gajewska, "Uwiedzeni przez manekiny, czyli o erotyce sztucznych ciał (na przykładzie opowiadania „Płaszcz Józefa Olenina" Eugène'a Melchiora de Vogüé)", Przestrzenie Teorii, no. 2 (2011): 69-80.

Slavoj Žižek, Looking Awry: An Introduction to Jacques Lacan Through Popular Culture (Cambridge: MIT Press, 1992), 80.

19 Pels analyzes this phenomenon by juxtaposing the attitudes towards magical things and "uncontrolled materiality" observed among West African communities and Europeans during the rise of colonialism. Pels, "The Spirit of Matter", 93-94. 
people to emphasize their social status and to shape their aesthetic and erotic image. Fashion and consumerism are allies of this creation, and place these objects in systems of supply and demand woven from notions of luxury and attractiveness, as evidenced by storefront displays of such items as lingerie and stockings in shopping malls and even directly facing the street (il. 1).

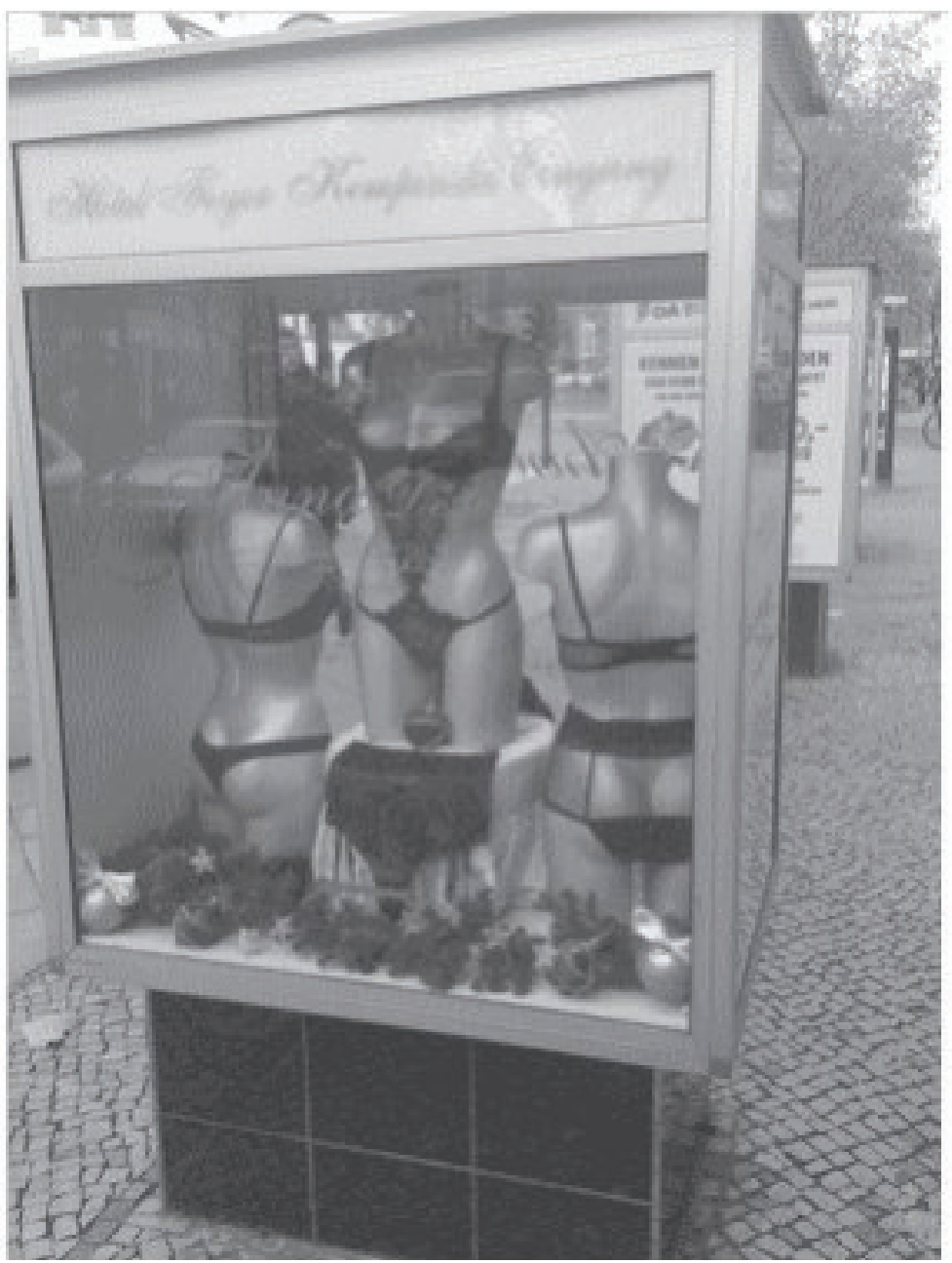

II. 1. Advertisement for a boutique at Kempinski Hotel Bristol, downtown Berlin, 2012. Photo by J. Kalinowski

Yet these systems often break, and consequently reject things that are perceived by society as being too bold, obscene, vulgar or a threat to morality 
or even to "good taste"; such objects are then relegated to a separate space, usually that of the sex shop. When examined from the anthropological perspective, erotic fetishes can be described as things that systems (e.g. fashion, consumerism) cannot entirely fill with meanings, but which will ultimately be harnessed by those systems and qualified as funny, frivolous, stimulating or arousing.

The two final qualifiers indicate the agency of these things: they elicit, or at least are intended to elicit, a certain response in people when placed in a certain context, and will be included in the erotic sphere as participants of the game.

\section{Strutting Like a Peacock: on the Allure of Animal Bodies}

The plot of Anatole France's 1908 novel Penguin Island begins on a polar island where St. Maël arrives and, taking the penguins inhabiting the island for little people, decides to make model Christians out of them. BookII begins with the parable The First Clothes, which tells of an experiment that was intended to reveal how penguins would react to other members of their species when the latter were dressed in clothing. A female penguin of average beauty was selected as the first being whose nakedness was to be covered up. She had "narrow shoulders, as slack chest, a stout and yellow figure, and short legs" Magis, the monk who initiated the experiment, ordered the animal to put on laced sandals, convinced that they would "give an elegant length to her legs and the weight they bear will seem magnified"22. A hat was then put on the female penguin, her arms and neck were encircled with jewelry, her abdomen was bound in a linen band, and her body was draped in a flowing tunic. Thus equipped, the penguin was allowed to walk away, and she provoked great interest wherever she went, particularly among the male part of the population:

A male penguin, who met her by chance, stopped in surprise, and retracing his steps began to follow her. As she went along the shore, others coming back from fishing, went up to her, and after looking at her, walked behind her. Those who were lying on the sand got up and joined the rest ${ }^{23}$.

Satisfied with the results of his experiment, the monk Magis explains to St. Maël that the clothing had increased her erotic attractiveness, which she

21 Anatole France, Penguin Island, trans. A.W. Evans (New York: Blue Ribbon Books, 1909), 45.

22 Ibid., 46.

23 Ibid., 47 . 
combines with mysteriousness and fantasy: "it was necessary that, ceasing to see it distinctly with their eyes, they should be led to represent it to themselves in their minds" $\mathbf{2 4}$.

This scene is one in a series of parables based on the Old Testament that discuss the creation of humans, their separation from animals, and the formation of social order and moral norms. Though this parable is clearly satirical in tone, it unmasks and mocks the ways in which social order is built and moral norms are shaped (and also lampoons political life in France at the turn of the 2oth century, in the latter half of the book), it nevertheless preserves the Judeo-Christian concept of humans who - as opposed to animals - cover their nakedness. I do not intend to analyze the issue of conscious nudity and the shame that, according to the Old Testament, Adam and Eve subsequently felt having eaten the apple from the tree in the Garden of Eden ${ }^{25}$. Rather, I am interested in the fact that the biblical characters put on clothes only after they had realized their heretofore taboo sexuality. In France's satirical work, the dressing of the character in clothing, shoes and a hat also produces the effect of "covering" that part, but at the same time it triggers the onlookers' fantasies, arousing their interest in the covered nakedness and increasing their erotic tension. In essence, Penguin Island expresses the idea that the passage from animality to humanity is a passage from sexuality to eroticism (the one so strongly emphasized one hundred years later by Paz, Bataille and Bauman), and that passage is tightly linked to the passage from the naked body to the clothed body. It is the clothing that makes the protagonist attractive and alluring.

The meaning of the scene described above is aptly conveyed by the German saying "the clothes make the man" (Kleider machen Leute), which is an anthropocentric notion that emphasizes the distinctiveness and uniqueness of humans vis-à-vis other species ${ }^{26}$. The posthumanist perspective, however, would eschew the stark dualism of naked animal vs. clothed human in favor of an approach that examines different ways of emphasizing one's attributes. While animals and insects are equipped with various signs of expression, e.g. the brightly-colored face of the mandrill, the pink sexual organs of the baboon, the spotted fur of the leopard and the turquoise-blue feathers of the peacock, the human body is devoid of such distinct qualities. Charles Darwin,

24 France, Penguin Island, 48.

25 As Giorgio Agamben observes, "Nudity, in our culture, is inseparable from a theological signature". Theologians emphasize the connection between sin and covering the body, as it was sin that caused them to feel ashamed of their nudity. See Giorgio Agamben, Nudities, trans. David Kishik and Stefan Pedatella (Stanford: Stanford University Press, 2010), 57-60. 
and later Wolfgang Welsch, emphasized the role that the colored bodies and plumage of animals, particularly males, play in their efforts to win the favor of females. In order for mating to occur, males must not only vie with other males, but also demonstrate their attractiveness to females and, by displaying their colorful plumage, skin or fur, attempt to convince the females to breed with them ${ }^{27}$. According to Darwin, curiosity and aesthetics play an important role in the selection of sexual partners. In his 1871 work The Descent of Man, and Selection in Relation to Sex, the scientist offered an interesting comparison: "It would even appear that mere novelty, or slight changes for the sake of change, have sometimes acted on female birds as a charm, like changes of fashion with us" 28 . In this view, there is a certain parallelism (but not identicalness) between animal and human aesthetics, and also between the development of the aesthetic sense in human and non-human animals, and their sex drive. Rather than being inherently human aesthetic phenomena, style and fashion are simply different ways of emphasizing one's physical attractiveness, ways that have developed over the course of human animal evolution. If, in the process of evolution, humans have lost the physical attributes once used to attract partners, perhaps they have compensated for this loss with clothing, makeup and jewelry. For now, this question remains unanswered. We do not know the sources of the human aesthetic sense (it is doubtful whether it can even be said to have a source, particularly from the evolutionary point of view) and most existing explanations represent a culturalist or anthropocentric viewpoint, or, conversely, erase the differences between human and non-human manifestations of aesthetics. Welsch admittedly warns us in Animal Aesthetics about "the methodological error of basing the question as to whether there is an aesthetics of animals on the basis of highly-developed human aesthetics as binding criteria"29, but he fails to explain the differences between the construction of an aesthetic sense in human and non-human animals. Welsch does emphasize the evolutionary continuity of aesthetics, but

27 In the world of animals males predominantly "dress up", luring and delighting the females who lack such refinements as rich colors or plumage as the male representatives of their species. However, one should not that in the world of human animals there were periods when the external manifestations of "dressing up" were equally peculiar to women and men. Moreover, the latter even led the way in this respect. An example of this is the fashion of the upper classes in 17th and 18th-century France, when men emphasized their status and attractiveness by wearing colorful frock-coats, shirts with frilling, shiny shoes with clasps, wigs bound with knots.

28 Charles Darwin, quoted in Wolfgang Welsch, "Animal Aesthetics", Contemporary Aesthetics no. 2 (2004), accessed July 29, 2015, http://hdl.handle.net/2027/spo.7523862.0002.015. 
he focuses primarily on animals and stops short of extracting the similarities and differences between the aesthetic sense developed through the course of evolution and the sense developed as a result of cultural change. On the sexual-erotic plane, Welsch reduces the aesthetic sense to a sender-receiver relationship that is strongly sex-based: males present a range of visual attributes such as the color of their fur or plumage, while females (note that in the animal world, females are not as generously endowed in this regard) select their mates based on aesthetic criteria and/or the fitness of the potential partners, in order to guarantee the best possible genes for their offspring.

This matter is more complicated in the human world, where biological factors overlap with cultural issues, leading to myriad configurations between nature and culture, or rather within natureculture (one word, emphasizing the ambivalence and simultaneous inseparability of these categories). Suffice it to mention that the physical attractiveness of a potential partner can be tied to the sexual and erotic satisfaction experienced in an act that only ends in pleasure, rather than in a sexual act that only serves to produce offspring and, from the evolutionary perspective, to ensure the survival of the species. In postmodern times, where sexual intercourse has been separated from procreation, courting the opposite sex need not be motivated by procreative goals. It should also be noted that, in different periods and cultures, courting the opposite sex was and is not exclusively the domain of men, and both women and men are known to adorn their bodies and pay attention to external attributes of attractiveness. While I warn against the error of transferring the animal (nature) onto the human (natureculture), I want merely to point out that the concern with aesthetic attributes for the purpose of attracting the opposite sex is as characteristic of humans as it is of non-human animals, but the creation of fashion, styles of dress, and the use of them as external signs of erotic and sexual attractiveness seems to be limited to humans (or has thus far only been observed in humans).

For these reasons, it is worth considering clothing and apparel as things created by people not merely for the purpose of protecting themselves against the cold and rain, but also to accentuate their erotic attractiveness. The attitude held by Westerners with regard to nakedness and clothing appears to run the gamut from acceptance to the lack of acceptance of the animal condition of humans, and is encumbered by theological, Judeo-Christian (i.e., cultural) roots, which I will attempt to demonstrate in the next part of this article.

\section{Seducing with Things}

I would venture the claim that human nakedness is a-erotic. This claim can be defended by analyzing the performance piece staged by Vanessa Beecroft at 
the Berlin Neue Nationalgalerie on April 8, 2005. One hundred naked women of various ages and races stood motionless, their faces expressionless, provoking consternation in the viewers, who were waiting in vain for something to occur. The women seemed completely a-erotic in their nakedness and indifference, as if the intimate tension had disappeared along with their clothing and underwear, leaving behind "nothing but nakedness", a quality of both human and non-human animals. The sole human touch was the shoes: translucent, high-heeled pumps covering the feet, and in some cases the calves, of the women, making the characters in the performance piece appear both clothed and unclothed; naked like animals, but clothed like humans; indifferent in their posture and facial expression, and yet displaying their bodies (long legs) by wearing the right style of footwear. The women participating in an earlier Beecroft performance at London's Gagosian Gallery (May 9, 2000) were also naked and simultaneously dressed in shoes and draped with gauze veils, as if human nakedness could only manifest itself through things, i.e., pieces of clothing.

In his examination of the problem of Western attitudes towards nudity, Giorgio Agamben finds these artistic events to be examples of theological thought, seeing the sparing and discrete use of clothing as the pursuit of a trace of the divine clothing of grace that clothed people in Paradise (they were nude, but not denuded, as their carnality was covered by clothing of grace) ${ }^{\mathbf{3 0}}$. The impossibility of returning to that state, caused by the sin of Adam and Eve, and the consequent donning of loincloths of fig leaves and, later, clothing, led to the development of a close association between nudity and clothing in our culture. The problem of sin and the consciousness of human sexuality and concupiscence also implies, in the theological sense, that clothing must be worn by humans (and only be humans, not other beings) as a kind of mark. From this perspective, clothing is closely associated not only with nakedness, but also with concupiscence.

The inseparable association between clothing and human concupiscence is manifested in many erotic or even soft-core pornographic images in which men and women rarely appear completely naked. Though the women featured in photo shoots (e.g. for the "Playboy" magazine) pose without clothing, they do wear shoes, garter belts, or at least jewelry, while men appear in their underwear or wear watches on their wrists, as if "naked carnality" were less attractive, less desirable than carnality equipped with additional accessories. In this sense, it is precisely the objects - garter belts, garters, corsets, heels, etc. - that make the body desirable (and, from the religious perspective,

30 Agamben, Nudities, 57. 
sinful). Many sex shops offer their customers dresses, lingerie and fishnet stockings that serve not to cover the body, but to emphasize its qualities (il. 2).

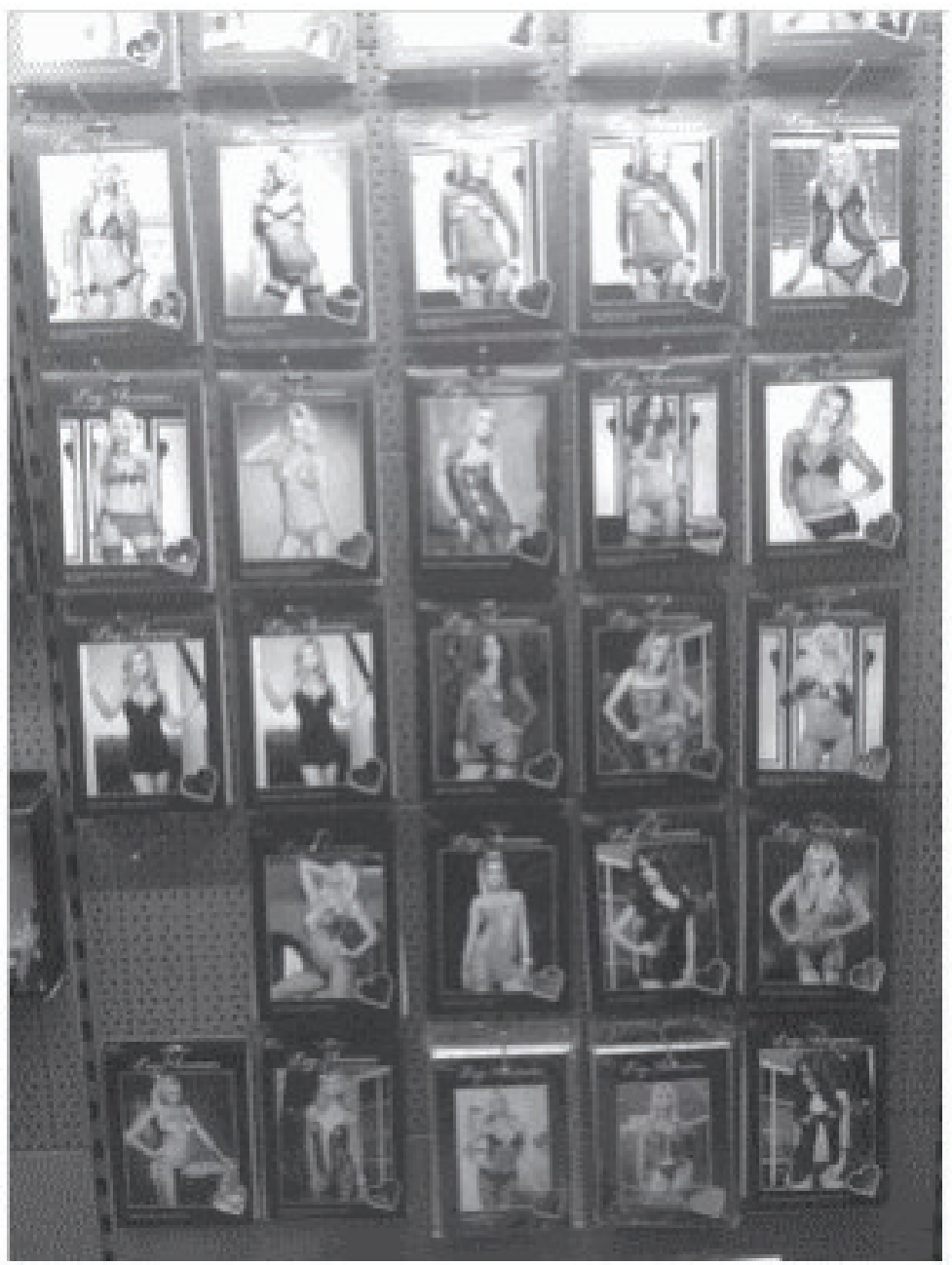

II. 2. Display case with fishnet lingerie and dresses at a sex shop, downtown Berlin, 2012. Photo by J. Kalinowski.

These objects are designed to evoke a certain response when worn on the human (usually female) body: to arouse the senses, stimulate erotic fantasies and to increase a person's sex drive. These objects are thus ascribed a certain agency that occurs in close correlation with the human subject. Though the 
objects do not initiate anything themselves, as they are not endowed with intentionality, in certain contexts, when they interact with a human who uses them and who looks at them, they can (and are designed to) provoke a certain reaction: stimulation, arousal. Meanwhile, exclusive shopping centers and lingerie manufacturers often reference notions of luxury coupled with notions of beauty and eroticism: lingerie is advertised by models whose beauty emphasizes the attractiveness of the product, which in turn emphasizes the beauty of the models (il. 3 ).

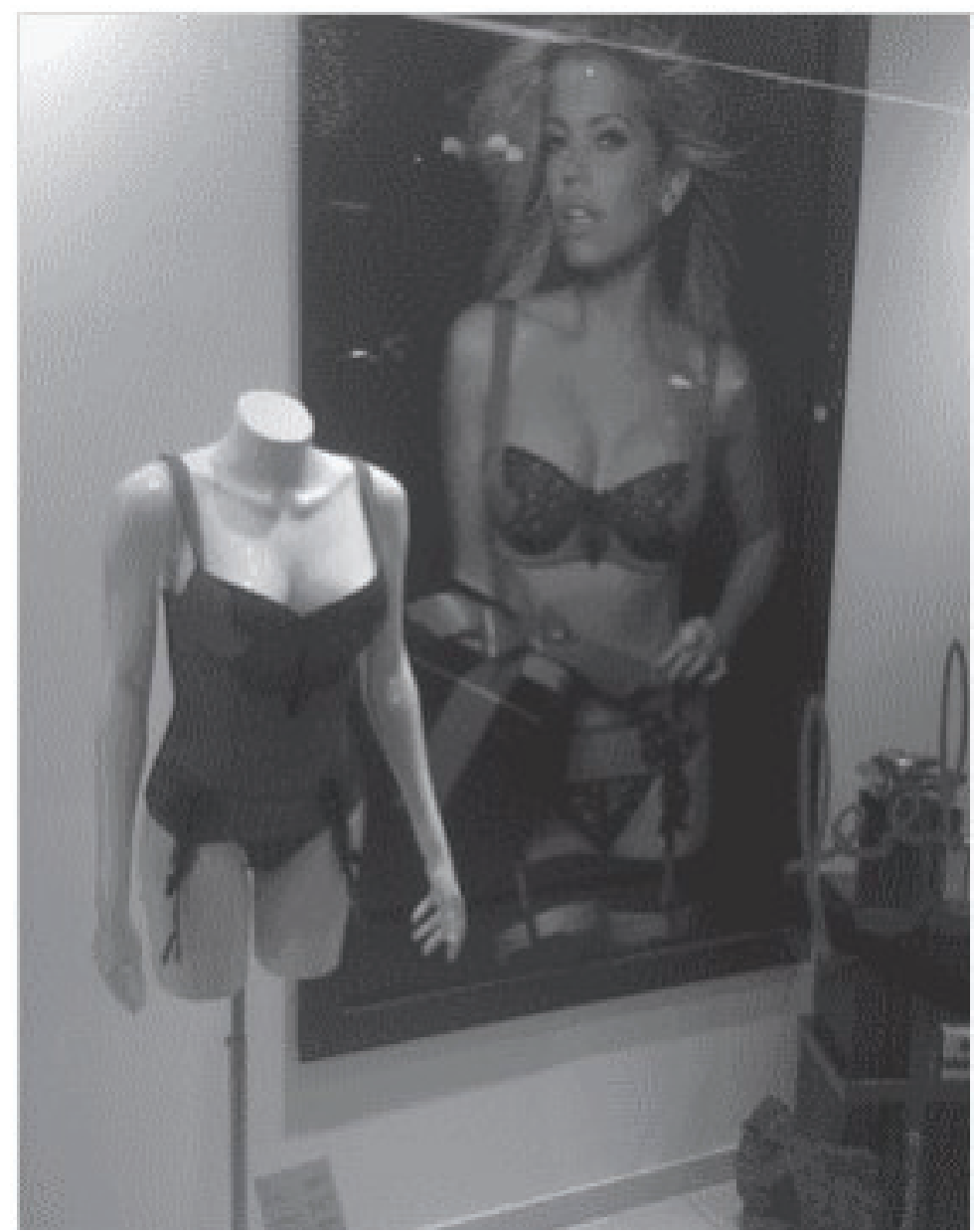

II. 3. Advertisement for lingerie at a boutique in a shopping center, Berlin, 2012. Photo by J. Kalinowski 
Fashion, consumerism and eroticism reinforce each other in advertising lingerie-objects, which become desirable in two ways: as luxury goods and as objects that accentuate the attractiveness of the human body.

\section{Conclusion}

The issue of human sexuality and eroticism is not a new topic in the humanities. Earlier studies focused primarily on the differences between sex and eroticism, classifying the former as a quality of animals (including human animals), while the latter as uniquely human. This point of view is entrenched in the anthropocentric perspective, as it emphasizes the uniqueness of human eroticism when contrasted with the universal sexuality and sex drive of other species. I do not claim that these premises are false, but I would avoid drawing a clear line between that which is human and that which is animal in the sexual and erotic sphere. Research conducted by Darwin and, in turn, posthumanists, suggest that the efforts made by non-human animals to attract partners are both complex and sophisticated, and that a broad repertoire of strategies (such as colorful plumage or fur, songs and mating dances) are deployed in order to arouse the partner. From the posthumanist perspective, it is more justifiable to speak of human and non-human animals as having various (though not identical) forms of emphasizing their own attributes than to stress the dichotomy between the animal (i.e., primitive) sexual instinct and the sophisticated human erotic sense. I believe that the repertoire of human strategies used to charm and attract the interest of a partner includes the use of things/objects/accessories, and it is here that I perceive the difference between the human erotic-sexual sphere and that of non-human animals. The preliminary study of the issue, the results of which I have presented in this article, involves such objects as clothing, lingerie and shoes, but does not exhaust the repertoire of erotically marked things and accessories.

The erotic and pornographic market offers whips, handcuffs, masks and other objects used by people to enhance and add variety to their sexual experiences. Objects such as these that bear the stigma of obscenity also warrant further investigation in the future. When we write about things, we should not forget about those that now share the biological space of the body, particularly implants and prostheses. From the perspective of posthumanism and the anthropology of objects, this theme can also open up new perspectives on the relationship between people and things in the sexual-erotic sphere. 